\title{
Synthesis of Malononitrile-Condensed Disperse Dyes and Application on Polyester and Nylon Fabrics
}

\author{
Yusuf Y. Lams, ${ }^{1}$ P. O. Nkeonye, ${ }^{2}$ K. A. Bello, ${ }^{2}$ M. K. Yakubu, $^{2}$ and A. O. Lawal ${ }^{3}$ \\ ${ }^{1}$ Department of Textile Technology and Fashion Design, College of Science and Technology, Kaduna Polytechnic, \\ PMB 2021, Kaduna, Nigeria \\ ${ }^{2}$ Department of Textile Science and Technology, Ahmadu Bello University, Zaria, Nigeria \\ ${ }^{3}$ Department of Applied Science, College of Science and Technology, Kaduna Polytechnic, PMB 2021, Kaduna, Nigeria
}

Correspondence should be addressed to Yusuf Y. Lams; yyakubulams@yahoo.com

Received 1 August 2014; Revised 28 October 2014; Accepted 8 November 2014; Published 8 December 2014

Academic Editor: Gajanan S. Bhat

Copyright (C) 2014 Yusuf Y. Lams et al. This is an open access article distributed under the Creative Commons Attribution License, which permits unrestricted use, distribution, and reproduction in any medium, provided the original work is properly cited.

An active methylene compound, malononitrile, was introduced into the structures of a series of disperse dyes previously prepared by coupling phloroglucinol, barbituric acid, and $\alpha$ and $\beta$-naphtho to 4 -amino-3-nitrobenzaldehyde. The dyes were purified by recrystallization from ethanol. The purity of the dyes was examined by thin-layer chromatography (TLC) and the dyes were characterized by visible absorption and Fourier transform infrared spectroscopy (FTIR). The malononitrile-condensed dyes produced deeper colours and shades with better fastness to wash, light, and perspiration on application to polyester and nylon fabrics when compared to their uncondensed analogue.

\section{Introduction}

Disperse dyes are substantially water-insoluble nonionic dyes which are applied to hydrophobic fibres (cellulose acetate, polyester, and nylon) from aqueous dispersions [1-5].

Disperse dyes are characterized by the absence of solubilizing groups and low molecular weight. From a chemical point of view, more than $50 \%$ of disperse dyes are simple azo compounds. About $25 \%$ are anthraquinones and the rest are methine, nitro, and naphthoquinone dyes [6]. The most dominant group of these dyes are the azo disperse dyes which account for approximately $60-70 \%$ of all disperse dyes manufactured [7-16].

The use of malononitrile (propanedinitrile, dicyanomethane; malonic (acid) dinitrile; propiodinitrile; methylene cyanide; cyanoacetic acid nitrile; malonitrile; malodinitrile) either as a coupling or diazo component or condensing agent with different chromophoric compounds in the synthesis of disperse dyes have been reported $[1,5,11-16]$. However, there seem to be no literatures on the condensation of disperse dyes derived from 4-amino-3-nitrobenzaldehyde coupled to phloroglucinol, barbituric acid, and $\alpha$ and $\beta$-naphthols with malononitrile. The present study reports the synthesis of new malononitrile-condensed disperse dyes and their application onto polyester and nylon fabrics.

Malononitrile was successfully introduced into the structures of four dyes (D1-4) previously prepared by the conventional diazotization and coupling methods to give dyes (D5-8) (see Figure 2). This was achieved by the Knoevenagel condensation in which a molecule of water was eliminated by way of nucleophilic addition of an active hydrogen compound (malononitrile) to a carbonyl group $(\mathrm{C}=\mathrm{O})$ contained in 4-amino-3-nitrobenzaldehyde followed by a dehydration reaction. The base in the reaction was piperidine. The products have larger molecular weight with usually higher melting points when compared with their parent compounds.

\section{Experimental}

2.1. Synthesis of 4-Amino-3-nitrobenzaldehyde (Diazo Component). 4-Acetylaminobenzaldehyde $(60 \mathrm{~g})$ was added to $150 \mathrm{~mL}$ acetic anhydride and heated to $105^{\circ} \mathrm{C}$ with vigorous stirring until it dissolved. The solution was cooled rapidly in ice-water to $30^{\circ} \mathrm{C}$ to produce a fine precipitate. $24 \mathrm{~mL}$ nitric acid and $60 \mathrm{~mL}$ acetic anhydride were carefully mixed, and 


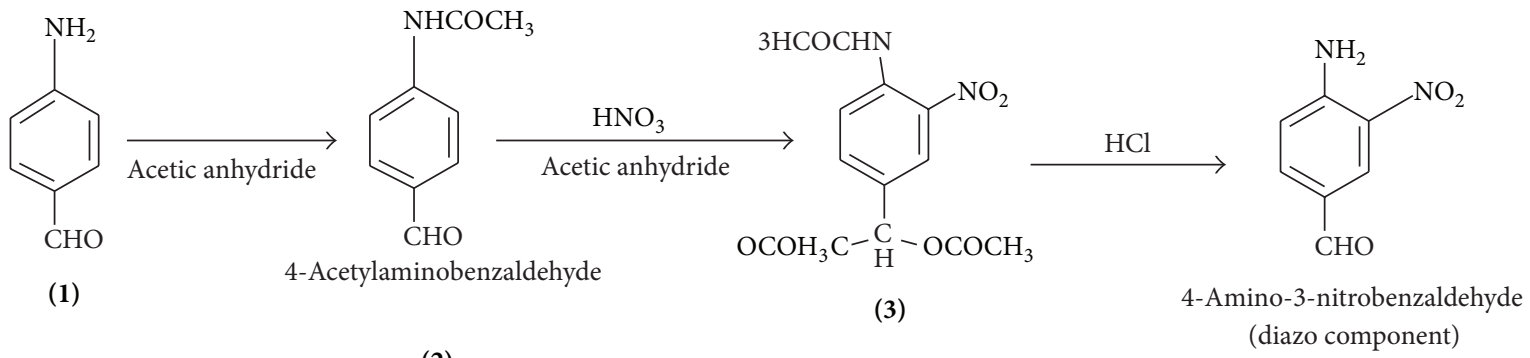

Scheme 1: Scheme for the synthesis of 4-amino-3-nitrobenzaldehyde.<smiles>O=Cc1ccc(N=Nc2c(O)cc(O)cc2O)c([N+](=O)[O-])c1</smiles>

D1<smiles>O=Cc1ccc(N=Nc2ccc(O)c3ccccc23)c([N+](=O)[O-])c1</smiles><smiles>O=Cc1ccc(N=NC2C(=O)NC(=O)NC2=O)c([N+](=O)[O-])c1</smiles>

D2<smiles>O=Cc1ccc(N=Nc2c(O)ccc3ccccc23)c([N+](=O)[O-])c1</smiles>

D4

FIgURE 1: Structures of dyes 1-4.

the mixture was added dropwise to the stirred suspension of 4-Acetylaminobenzaldehyde (2) at a rate that the temperature did not rise above $35^{\circ} \mathrm{C}$. The addition of about one-third of the acid produced colourless crystal deposits which have been shown by Hodgson\&Beard to be 4-acetylbenzalidene diacetate (3) [10]. Further drops of the acid dissolved the crystals with a gradual temperature rise up to $50^{\circ} \mathrm{C}$. The mixture was stirred at this temperature for a further 15 minutes and poured into $800 \mathrm{~mL}$ ice-water. The precipitated 4-acetylamino-3-nitrobenzalidene diacetate was filtered off, washed thoroughly with ethanol, and then with water before it was dried. Recrystallisation from ethanol produced $93 \%$ of the diacetate as pale yellow leaflets $(64 \mathrm{~g})$ with a m.p. of 112$113^{\circ} \mathrm{C}$.

The diacetate $(60 \mathrm{~g})$ was added to concentrated hydrochloric acid $(170 \mathrm{~mL})$ and heated on a water bath for $15 \mathrm{~min}$. After cooling, $257 \mathrm{~mL}$ water was added and the precipitated 4amino-3-nitrobenzaldehyde (4) was filtered off, washed with water and dried. It was purified by recrystallisation from water, to produce orange needle like substance with m.p. of $188-190^{\circ} \mathrm{C}$ (see Scheme 1).

2.2. Diazotisation of 4-Amino-3-nitrobenzaldehyde. 4-amino3-nitrobenzaldehyde (3.2 g, $0.02 \mathrm{~mol})$ was added to a mixture of acetic acid $(24 \mathrm{~mL})$ and water $(6 \mathrm{~mL})$ and cooled with stirring to $12^{\circ} \mathrm{C}$. Sodium nitrite $(1.5 \mathrm{~g}, 0.02 \mathrm{~mol})$, dissolved in $10 \mathrm{~mL}$ of water, was added in one portion and $10 \mathrm{~mL}$ of concentrated hydrochloric acid was added immediately. The mixture was maintained at $15-20^{\circ} \mathrm{C}$ for $15 \mathrm{~min}$, and then excess nitrous acid was destroyed by addition of small amount of urea. The solution was diluted with $200 \mathrm{~mL}$ ice-water to achieve $0-5^{\circ} \mathrm{C}$ and produced a clear solution of the diazonium salt (5). See Figure 3.

2.3. Coupling of Diazotised 4-Amino-3-nitrobenzaldehyde to Various Coupling Components. The solution of the various coupling components was cooled to $0-5^{\circ} \mathrm{C}$ and was treated with a cold $\left(0-5^{\circ} \mathrm{C}\right)$ of the diazonium salt (Scheme 2$)$ as prepared above, to produce dyes D1-4 (Figure 1). Same procedure was followed to prepare coupling solutions with the substituted coupling components.

2.4. Condensation of Aldehyde Dyes Derived from 4-Amino3-nitrobenzaldehyde with Malononitrile. 0.006 mole of the azo dye and 0.006 mole of malononitrile were dissolved with warming in absolute ethanol $\left(150 \mathrm{~cm}^{3}\right)$. One drop of piperidine was added and the mixture was refluxed for 15 minutes. On cooling, the product generally crystallized out and was filtered off and recrystallized from ethanol (Scheme 3).

2.5. Purification of Synthesized Dyes. The dyes were purified by recrystallization from ethanol and their purity examined by thin-layer chromatography (TLC). 



FIGURE 2: Structures of malononitrile-condensed disperse dyes (D5-8) derived from 4-amino-3-nitrobenzaldehyde.<smiles>Nc1ccc(C=O)cc1[N+](=O)[O-]</smiles>

4-Amino-3-nitrobenzaldehyde
4-Formyl-2-nitrobenzenediazonium chloride

(5)

Figure 3

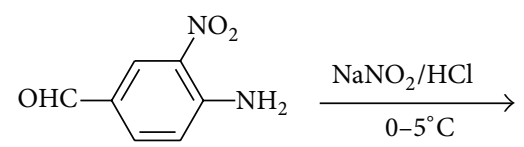

4-Amino-3-nitrobenzaldehyde<smiles></smiles><smiles>C[13CH][13CH]</smiles><smiles>[R]N=Nc1ccc(C=O)cc1[N+](=O)[O-]</smiles>

Where $R_{1}$ is the coupling component

Scheme 2: Scheme for the synthesis of aldehyde dyes (D1-4) derived from 4-amino-3-nitrobenzaldehyde. 
TABLE 1: Yield, colour, molecular weight and melting points of dyes derived from Diazo component.

\begin{tabular}{|c|c|c|c|c|c|c|}
\hline Dye & $\begin{array}{l}\text { Coupling component } \\
\qquad \mathrm{R}_{1}\end{array}$ & Weight of Dye & $\%$ yield & Colour of crystals & Mol. wt (g) & $\begin{array}{l}\text { Melting point } \\
\left({ }^{\circ} \mathrm{C}\right)\end{array}$ \\
\hline D1 & & 1.969 & 65 & Coffee-brown & 303 & $205-207$ \\
\hline D2 & & 2.288 & 75 & Yellow & 309 & 222 \\
\hline D3 & & 2.022 & 63 & Light-orange & 321 & $128-130$ \\
\hline D4 & & 2.183 & 68 & Dark-red & 321 & 110-112 \\
\hline $\begin{array}{l}\text { Diazo } \\
\text { Component }\end{array}$ & . & & & & & \\
\hline
\end{tabular}

$\mathrm{R}_{1}$ : the coupling component.<smiles>[R1]N=Nc1ccc(C=[R])cc1[N+](=O)[O-]</smiles>

Where $R_{1}$ is the coupling component and

$\mathrm{R}_{2}$ is the active methylene compound (malononitrile)

Scheme 3: Scheme for the synthesis of malononitrile-condensed disperse dyes derived from 4-amino-3-nitrobenzaldehyde.

2.6. Characterization of the Dyes. The dyes were characterized by visible absorption spectroscopy using Unicam SP 800 spectrophotometer, IR spectral bands obtained from Pekin Elmer 100 FT-IR spectrophotometer.

The molar extinction coefficient presented in Table 3 was calculated using Beer Lambert's law.

\subsection{Application of the Synthesized Dyes onto the Substrates (Dyeing)}

2.7.1. Application to Polyester. The dye bath was made up of $2 \%$ o.w.f. (dye), $1.5 \mathrm{~mL}$ chlorobenzene (carrier), and $50: 1$ (liquor ratio) at $100^{\circ} \mathrm{C}$. The fabric $(10 \mathrm{~cm}$ by $10 \mathrm{~cm})$, after being wetted and thoroughly squeezed to remove excess water, was immersed into the bath at $50^{\circ} \mathrm{C}$ and allowed to reach the boil within 15 minutes. Dyeing was continued at the boil for 1 hour with constant agitation. At the end of dyeing, the substrate was removed, squeezed, and rinsed thoroughly under a running tap and allowed to dry at room temperature.
2.7.2. Application to Nylon. The dye bath was made up of $2 \%$ o.w.f. (dye) and $50: 1$ (liquor ratio) at $100^{\circ} \mathrm{C}$. The fabric $(10 \mathrm{~cm}$ by $10 \mathrm{~cm})$, after being wetted and thoroughly squeezed to remove excess water, was immersed into the bath at $50^{\circ} \mathrm{C}$ and allowed to reach the boil within 15 minutes. Dyeing was continued at the boil for 1 hour with constant agitation. At the end of dyeing, the substrate was removed, squeezed, and rinsed thoroughly under a running tap and allowed to dry at room temperature.

2.7.3. Reduction Clearing. The dyed material was treated in a bath containing $1.5 \mathrm{~g} / \mathrm{L}$ dispersing agent, $2 \mathrm{~g} / \mathrm{L}$ caustic soda, and $2 \mathrm{~g} / \mathrm{L}$ sodium dithionite at $60^{\circ} \mathrm{C}$ for 30 minutes. This was aimed at removing unfixed dye and carrier residues that may be left on the fabric after dyeing.

2.8. Results and Discussion. The yield, colour, molecular weight, and melting points of synthesized dyes 1-4 and condensed dyes 5-8 are presented in Tables 1 and 2, respectively. 
TABLE 2: Yield, colour, molecular weight and melting points of condensed dyes derived from the Diazo component.

$\begin{array}{cccccc}\text { Dye } \begin{array}{c}\text { Condensed } \\ \text { Dye }\end{array} & \begin{array}{c}\text { Coupling component } \\ \text { component }\end{array} & \begin{array}{c}\text { Weight of } \\ \text { Dye }\end{array} & \begin{array}{c}\text { \% yield } \\ \text { Colour of crystals Mol. wt (g) }\end{array} \text { Melting } \\ \text { point }\left({ }^{\circ} \mathrm{C}\right)\end{array}$

$\mathrm{R}_{1}$ : the coupling component, $\mathrm{R}_{2}$ : the condensing component.

TABLE 3: Absorbance and $\lambda_{\max }$ of dyes derived from 4-amino-3-nitrobenzaldehyde in different solvents (UV spectral properties of dyes).

\begin{tabular}{|c|c|c|c|c|c|c|}
\hline Dye & $\begin{array}{c}\text { Ethanol } \\
\text { A }\end{array}$ & $\begin{array}{c}\text { Acetone } \\
\text { B }\end{array}$ & $\begin{array}{c}\text { Dimethyl } \\
\text { Formamide } \\
\text { C }\end{array}$ & $\begin{array}{c}\text { Ethanol + HCL } \\
\text { D }\end{array}$ & $\begin{array}{c}\text { Change in } \lambda_{\max } \\
\mathrm{A}-\mathrm{D}\end{array}$ & $\begin{array}{c}\text { Molar extinction } \\
\text { Coefficient in DMF } \\
\text { LIT MOL }{ }^{-1} \mathrm{CM}^{-1} \times 10^{4}\end{array}$ \\
\hline D1 & 680 & 440 & 549 & 436 & -244 & 4.361 \\
\hline D2 & 450 & 451 & 459 & 447 & -3.0 & 2.640 \\
\hline D3 & 489 & 532 & 470 & 532 & +43 & 3.478 \\
\hline D4 & 532 & 500 & 548 & 486 & -46 & 3.969 \\
\hline D5 & 602.0 & 551.5 & 651 & 780.5 & +178.5 & 1.520 \\
\hline D6 & 455.5 & 553.0 & 484 & 456.5 & +1.0 & 2.540 \\
\hline D7 & 456 & 461 & 667 & 453 & -3.0 & 5.016 \\
\hline D8 & 561.0 & 550.0 & 559 & 557 & -4.0 & 4.395 \\
\hline
\end{tabular}

The UV/visible and IR spectral characteristics of the dyes indicate that they absorbed at very high wavelengths up to $680 \mathrm{~nm}$ for dye 1 and near infra-red region up to $780.5 \mathrm{~nm}$ for dye 5. The presence of the main functional groups such as carbonyl $(\mathrm{C}=\mathrm{O})$, azo $(\mathrm{N}=\mathrm{N})$, nitrile $\mathrm{C} \equiv \mathrm{N}$, nitro $\left(\mathrm{NO}_{2}\right)$, and hydroxyl $(\mathrm{OH})$, in the structures of the dyes as presented in Table 3 and Figure 1 was established.

The solvatochromic study of the dyes was measured in acetone, dimethylformamide (DMF), and ethanol [9]. The results showed that the dyes absorbed at much higher wavelengths in DMF, an indication that DMF has greater polarity towards the dyes than the other solvents. The halochromism (effect of few drops of acid on the visible absorption band) of the dyes was studied in ethanol. The dyes exhibited both positive and negative halochromism on addition of one drop of hydrochloric acid to ethanol as indicated in Table 3.
The condensation of the aldehyde dyes with the active methylene compound (malononitrile) imparted significantly on light absorption of the corresponding dyes. It is believed that malononitrile caused increase in resonance which in turn increased the intensity of absorption of light and consequently shifting absorption bands to longer wavelengths.

2.8.1. Infrared Spectral Characteristics of the Synthesized Dyes. Infrared spectra of the synthesized dyes were measured in KBr pellets on a Perkin-Elmer 100 FTIR spectrophotometer. The results are shown in Table 4.

The spectral results of dyes $5,6,7$, and 8 as presented in Table 4 showed characteristic bands around 2900$3088.67 \mathrm{~cm}^{-1}$ indicating the presence of aromatic $\mathrm{C}-\mathrm{H}$ stretching vibration. The aliphatic $\mathrm{C}-\mathrm{H}$ bending vibration 


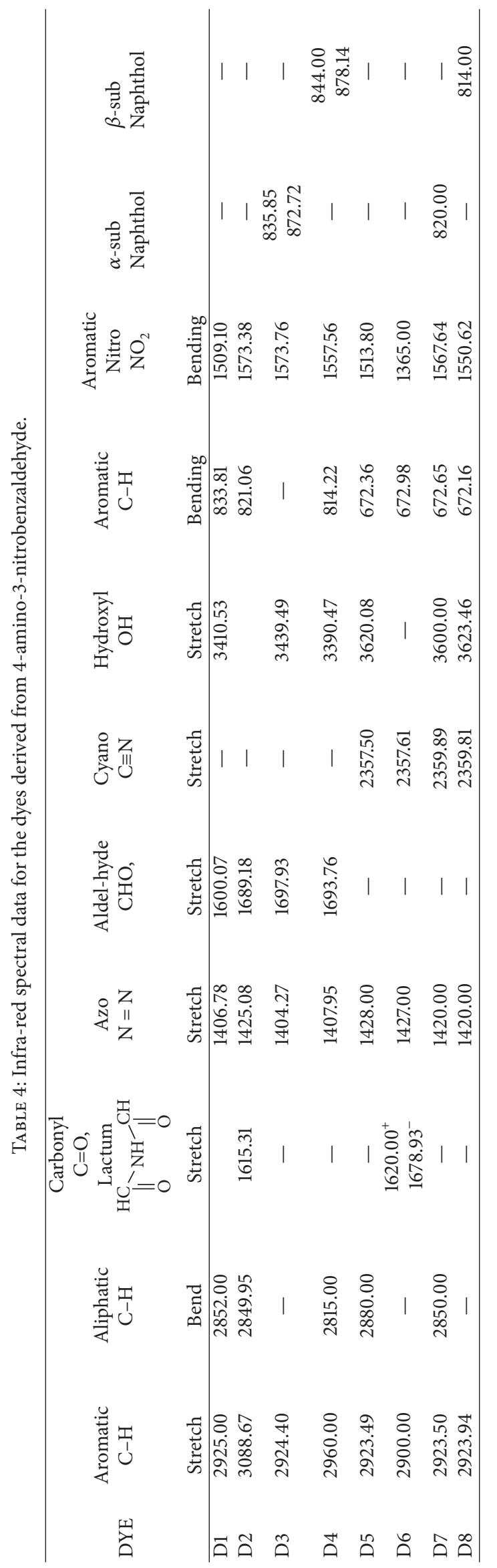


TABLE 5: Wash, light and perspiration fastness of dyes derived from 4-amino-3-nitrobenzaldehyde on polyester and nylon fabrics.

\begin{tabular}{lcccccccccccccc}
\hline & \multicolumn{4}{c}{ Fastness to Wash } & \multicolumn{4}{c}{ Fastness to Light } & \multicolumn{4}{c}{ Fastness to Perspiration } \\
Dye & \multicolumn{2}{c}{ Polyester } & \multicolumn{2}{c}{ Nylon } & \multicolumn{4}{c}{ Polyester } & \multicolumn{3}{c}{ Nylon } \\
& CSH & STN & CSH & STN & Polyester & Nylon & \multicolumn{2}{c}{ ACD } & ALK & \multicolumn{2}{c}{ ACD } & ALK \\
& & & & & & & CSH & STN & CSH & STN & CSH & STN & CSH & STN \\
\hline D1 & $4-5$ & $3-4$ & $4-5$ & $4-5$ & 3 & 7 & 5 & $4-5$ & 5 & $4-5$ & 4 & $1-2$ & 5 & $4-5$ \\
D2 & $4-5$ & $4-5$ & $4-5$ & 5 & 7 & 7 & 4 & 4 & 4 & $4-5$ & 5 & $4-5$ & 5 & 5 \\
D3 & $4-5$ & $4-5$ & $4-5$ & $3-4$ & 7 & 5 & 4 & $3-4$ & 5 & $4-5$ & 4 & 4 & 5 & 5 \\
D4 & 5 & 5 & $4-5$ & $3-4$ & 7 & 7 & 3 & $2-3$ & 4 & $3-4$ & 4 & $4-3$ & 5 & $4-5$ \\
D5 & 5 & 5 & 5 & 5 & 4 & 7 & 4 & $3-4$ & 5 & $4-5$ & 4 & $4-5$ & 5 & 5 \\
D6 & 5 & 5 & $4-5$ & 5 & 7 & 7 & 5 & 4 & 5 & 4 & 5 & 5 & 5 & 4 \\
D7 & 5 & 5 & $4-5$ & $4-5$ & 5 & 5 & 3 & 2 & 3 & 3 & 2 & $3-4$ & 2 & 3 \\
D8 & 5 & 5 & 5 & $4-5$ & 7 & 7 & 5 & 3 & 5 & $4-5$ & 5 & 5 & 5 & 5 \\
\hline
\end{tabular}

occurred at $2815-2880 \mathrm{~cm}^{-1}$. Absorption peaks due to lactum group in dyes 2 and 6 appeared at $1620 \mathrm{~cm}^{-1}$ and $1678.93 \mathrm{~cm}^{-1}$, respectively. The strong bands which appeared around $1615-1695 \mathrm{~cm}^{-1}$ are due to carbonyl $(\mathrm{C}=\mathrm{O})$ stretching vibration. The bands $1404-1428 \mathrm{~cm}^{-1}$ arise from the presence of azo group $(\mathrm{N}=\mathrm{N})$ while the broad peak around 3390$3623 \mathrm{~cm}^{-1}$ is due to aromatic $(\mathrm{ArOH})$ stretching vibration. Other important absorption bands that appeared in the aldehyde dyes include $2357.50-2359.89 \mathrm{~cm}^{-1}(\mathrm{C} \equiv \mathrm{C})$ stretching vibration for Dyes 5, 6, 7, and $8 ; 1509.10-1573.38 \mathrm{~cm}^{-1}$ nitro group $\left(\mathrm{NO}_{2}\right)$ bending vibration for Dyes 1 and 3; 1600.07$1697.93 \mathrm{~cm}^{-1}$ aromatic (CHO) stretching vibration for Dyes 1 and $3 ; 820-872.72 \mathrm{~cm}^{-1}(\alpha$-substituted naphthol) for Dyes 3 and 7 and $814-878 \mathrm{~cm}^{-1}$ ( $\beta$-substituted naphthol) for Dyes 4 and 8 respectively. Absorption peaks due to $\mathrm{N}-\mathrm{H}$ bending vibration were observed at $1509 \mathrm{~cm}^{-1}$ and $1504 \mathrm{~cm}^{-1}$ for Dyes 5 and 6, respectively. Further studies with NMR will help or likely confirm the observations made based on the FTIR.

2.8.2. Fastness Properties of Synthesized Dyes. The dyes 18 were applied at $2 \%$ depth on the polyester and nylon fabrics. Their wash, light, and perspiration fastness are given in Table 5.

A remarkable degree of levelness and brightness was observed after washing. This is a clear indication of good penetration and excellent affinity of these dyes to the fabrics.

The dyeing showed very good (4-5) to excellent (5) washing fastness generally on both polyester and nylon fabrics. The results from Table 5 show good (5) to excellent (7) light fastness properties for most of the dyes, except for dye $\mathbf{1}$ that was relatively poor (3). The observed higher fastness can be explained in terms of the reduction of the electron density at the azo group due to the inductive effect exerted by the $\mathrm{CN}$ group.

Fastness to perspiration averaged very good (4) to excellent (5) for most of the dyes. However, dye 7 gave poor fastness on both polyester and nylon. This is perhaps due to the weak hydrogen bond on $\alpha$-position on the naphthalene structure. The results indicate that majority of the dyes showed better perspiration properties to alkali than acid.
Generally, the malononitrile-condensed dyes provided better fastness to wash, light, and perspiration when compared with their uncondensed counterparts. This is thought to be due to increased molecular size and conjugation.

\section{Conclusion}

A series of new monoazo disperse dyes were produced by coupling diazotized 4 -amino-3-nitrobenzaldehyde and their derivatives to different coupling components. The dyes provide a wide range of attractive colours varying from peach, yellow, and orange, to amber, brown, purple, violet, bluish, and greenish shades on fibre and offer excellent affinity and intensity of colour. The intrinsic conjugation in the nitrobenzaldehyde structure results in high bathochromic shifts and lead to brightness of shades. The nature of the substituent in the coupling components has a great influence on the visible absorption and shade of dying. Most dyes showed very good exhaustion and leveled and uniform dyeing. The remarkable degree of levelness after washing is a clear evidence of the good penetration and affinity of the dyes to the fabrics on which they were applied. The barbituric and naphthalene substituted dyes generally showed better fastness properties than their hydroylated analogues. The condensed dyes provided better fastness to wash, light, and perspiration when compared with their uncondensed counterparts. This is thought to be due to increased molecular size and conjugation. The compactness of the polyester fibre structure accounts for these dyes' superior fastness properties on it than nylon.

\section{Conflict of Interests}

The authors declare that there is no conflict of interests regarding the publication of this paper.

\section{Acknowledgment}

The authors are grateful to the Department of Chemistry, University of Kwazulu-Natal, South Africa, for granting them permission to carry out the FT-IR analysis of the dyes in the instrumentation laboratory. 


\section{References}

[1] A. M. Al-Etaibi, M. A. El-Apasery, M. R. Ibrahim, and N. A. Al-Awadi, "A facile synthesis of new monoazo disperse dyes derived from 4-hydroxyphenylazopyrazole-5-Amines: evaluation of microwave assisted dyeing behavior," Molecules, vol. 17, no. 12, pp. 13891-13909, 2012.

[2] Y. Y. Lams, P. O. Nkeonye, K. A. Bello, M. K. Yakubu, and A. O. Lawal, "Synthesis of disperse dyes from pyridone and resorcinol coupled to diazotized 2-amino-4-chloro-5-formylthiazole and application to polyester," Advances in Chemistry, vol. 2014, Article ID 864286, 7 pages, 2014.

[3] A. A. Fadda and K. M. Fadda, "Synthesis of novel azo disperse dyes derived from 4-aminoantipyrine and their applications to polyester fabrics," The American Journal of Organic Chemistry, vol. 2, no. 3, pp. 52-57, 2012.

[4] Y. S. Choi, K. S. Lee, H. J. Kim et al., "Synthesis, spectral property and dyeing assessment of azo disperse dyes containing carbonyl and dicyanovinyl groups," Bulletin of the Korean Chemical Society, vol. 34, no. 3, pp. 863-867, 2013.

[5] J. Koh, M.-J. Oh, H. Kim, and S. D. Kim, "Alkaline dissolution monitoring of radial-type polyester microfiber fabrics by a cationic dye-staining method," Journal of Applied Polymer Science, vol. 99, no. 1, pp. 279-285, 2006.

[6] P. A. Eigenmann and C. A. Haegelliand, "Food colouring and preservative-allergy and hyperactivity," Archives of Disease in Childhood, vol. 90, p. 875, 2004.

[7] A. S. Abd-El-Aziz and T. H. Afifi, "Novel azo disperse dyes derived from aminothiophenes: synthesis and UV-visible studies," Dyes and Pigments, vol. 70, no. 1, pp. 8-17, 2006.

[8] Internet International Union of Pure and Applied Chemistry, "Azo compounds," Compendium of Chemical Terminology, 2009.

[9] A. Marini, M. Aurora, B. Alessendro, and M. Benedetha, "What is solvatochromism?" Chemistry Journal of Physical Chemistry $B$, vol. 114, no. 51, pp. 117128-117135, 2010.

[10] K. A. Bello, "Long wavelength absorbing azo dyes derived from 2-amino-4-chloro-5-formylthiazole as diazo component," Dyes and Pigments, vol. 27, no. 1, pp. 45-54, 1995.

[11] H. R. Maradiya and V. S. Patel, "Synthesis and application of disperse dyes based on 2-aminothiazole derivatives," Chemistry of Heterocyclic Compounds, vol. 39, no. 3, pp. 357-363, 2003.

[12] M. M. El-Molla, Z. H. Ismaeil, F. M. A. Soliman, H. Shaimaa, and A.-E. Monem, "Synthesis of several newly disperse dyes and their application in textile printing," Journal of the Textile Association, vol. 74, no. 1, pp. 18-25, 2013.

[13] S. K. Zadafiya, J. H. Tailor, and G. M. Malik, "Disperse dyes based on thiazole, their dyeing application on polyester fiber and their antimicrobial activity," Journal of Chemistry, vol. 2013, Article ID 851418, 5 pages, 2013.

[14] P. O. Nkeonye, Fundamental Principles of Textile Dyeing, Printing and Finishing, Ahmadu Bello University Press, 1987.

[15] A. Marini, A. Muñoz-Losa, A. Biancardi, and B. Mennucci, "What is solvatochromism?" Journal of Physical Chemistry B, vol. 114, no. 51, pp. 17128-17135, 2010.

[16] P. Parvizi, A. Khosravi, S. Moradian, and K. Gharanjig, "Synthesis and application of some alkali-clearable azo disperse dyes based on naphthalimide derivatives," Journal of the Chinese Chemical Society, vol. 56, no. 5, pp. 1035-1042, 2009. 

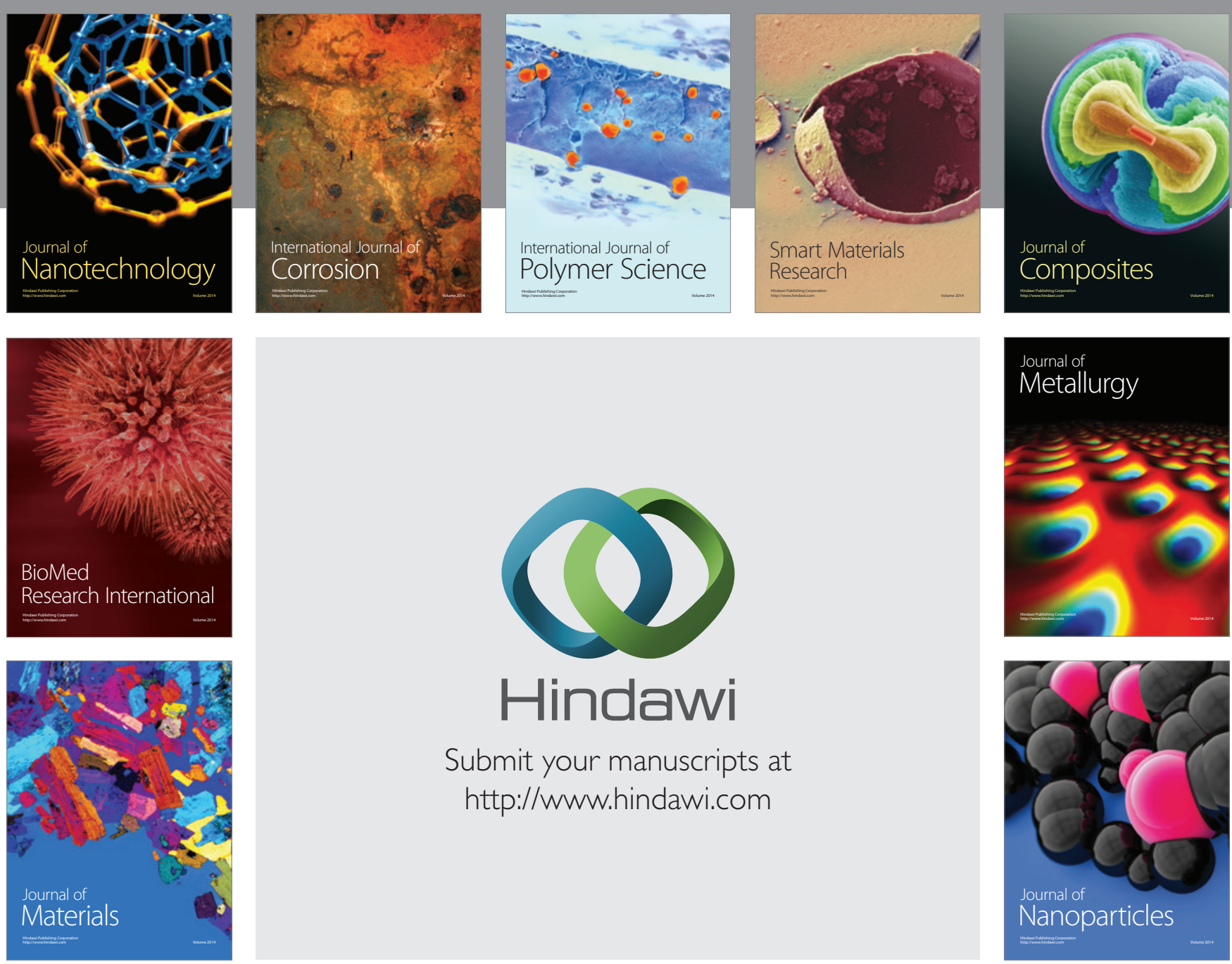

Submit your manuscripts at http://www.hindawi.com
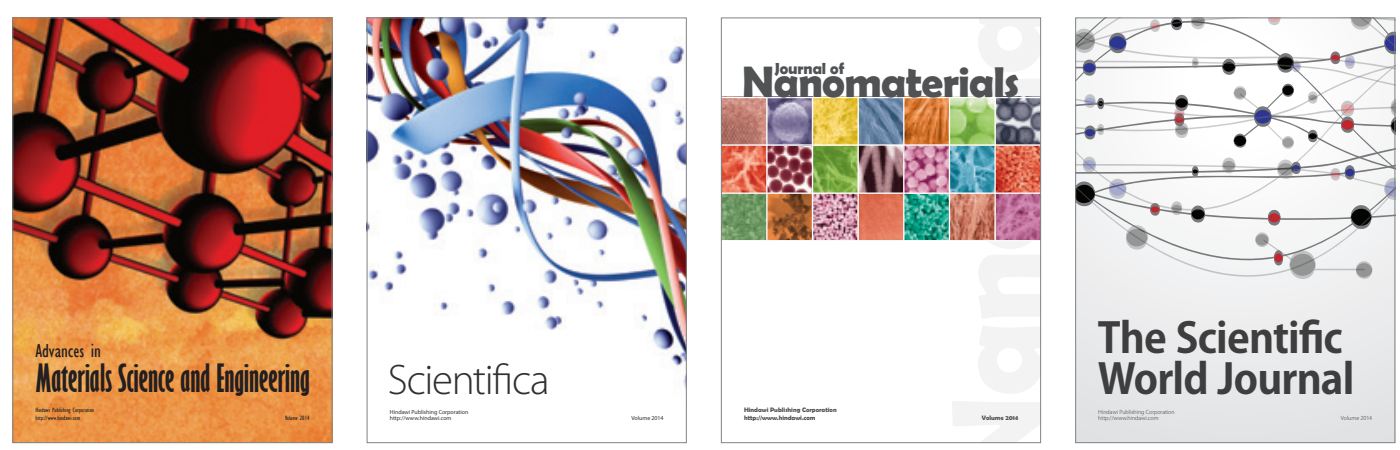

\section{The Scientific World Journal}
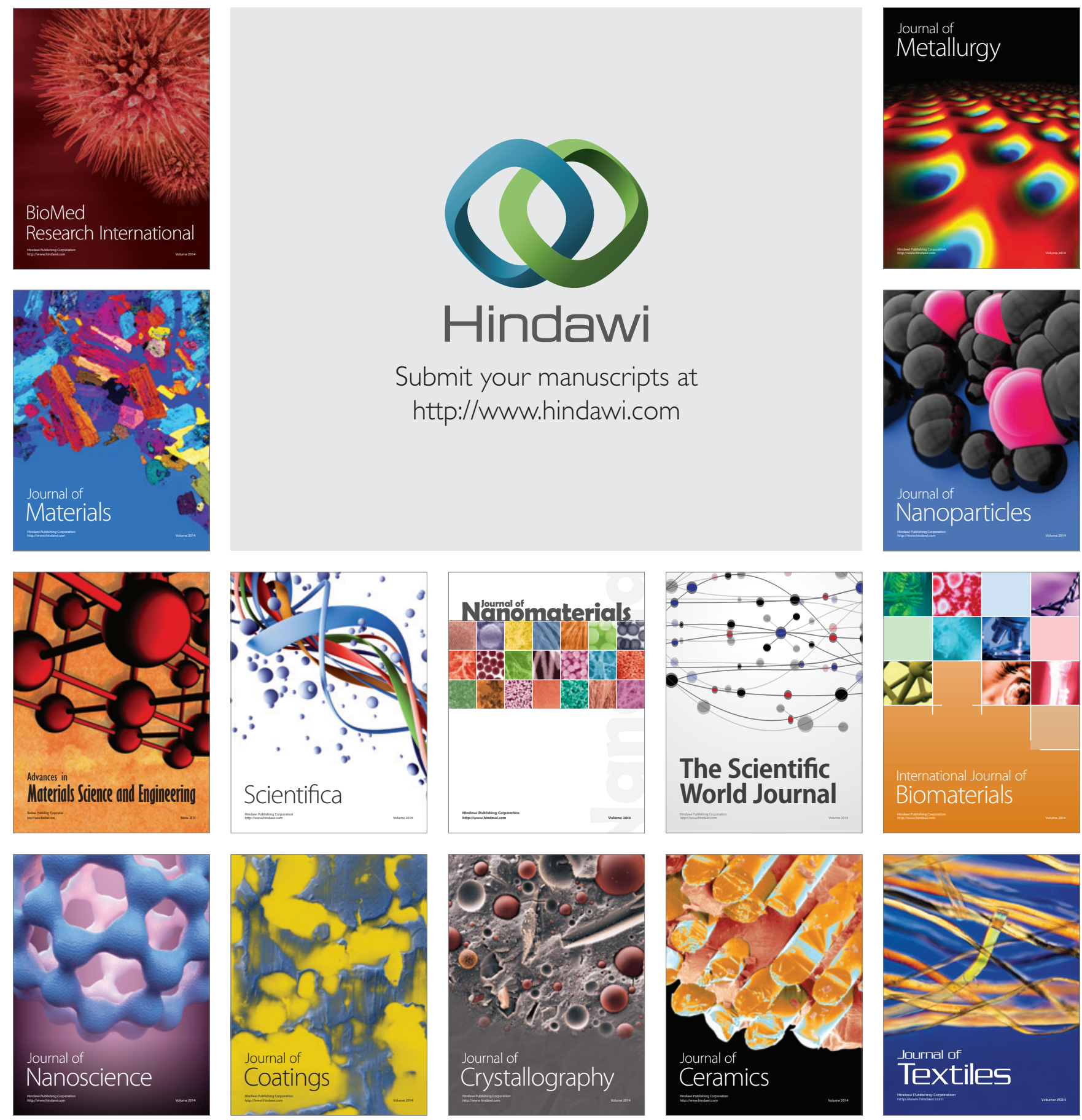